\title{
Epidermal differentiation and dermal changes in healing following treatment of surgical wounds with sheets of cultured allogeneic keratinocytes
}

\author{
S R Myers, H A Navsaria, A N Brain, P E Purkis, I M Leigh
}

\begin{abstract}
Aims-To establish the structural changes that occur in deep surgical wounds engrafted with allogeneic sheets, their time course and inter-relation.

Methods-Deep surgical wounds following shave excision of tattoos (down to deep dermis/subcutaneous fat) were treated with sheets of sex mismatched allogeneic keratinocytes in 19 patients and then biopsied weekly until wound healing was complete. More superficial surgical wounds-that is, 20 standard skin graft donor sites, were biopsied at seven to 10 days (all healed) following application of keratinocyte allografts. All biopsy specimens were examined with a large panel of monoclonal antibodies to keratins, envelope proteins, basement membrane components, and to extracellular matrix components.

Results-The hyperproliferative keratin pair K6/16 was expressed in all wounds, for up to six weeks in keratinocyte grafted deep wounds, and up to six months in split thickness skin grafted wounds.

Conclusions-Keratins 6 and 16 have not been detected in normal skin, although the relevant mRNA has. This raises the possibility of regulation at a post-transcriptional level allowing a rapid response to injury with cytoskeletal changes that may aid cell migration. This keratin pair offers the most sensitive marker for altered epidermis following wounding.

(f Clin Pathol 1995;48:1087-1092)
\end{abstract}

Keywords: Wound healing, keratinocyte, keratins, allograft.

The development of keratinocyte culture techniques in the 1970 s and early 1980 s meant that a given population of cells could be expanded from a small skin biopsy specimen into a large area of cultured keratinocytes by serial passaging. ${ }^{1}$ The potential use of this tissue expansion technique for skin grafts was recognised and such cultured grafts are now in clinical and commercial use. ${ }^{23}$ Earliest reports of keratinocyte grafting came from burns centres. Patients with very extensive burns were treated successfully with sheets of cultured autologous keratinocytes (keratinocyte autografts). ${ }^{4}$ The experience has gradually extended to involve multiple burns centres in USA, Europe and Japan. In 1983 Hefton et aP reported the use of keratinocyte allografts in the treatment of initially three, and subsequently 22 patients with burns. ${ }^{6}$ Clinical "take" and good results were observed, and speculation to explain this phenomenon was based on the known loss of antigen presenting Langerhans cells in the cultures, suggesting that keratinocyte allografts might not be rejected. ${ }^{7}$ However, cultured keratinocytes retain the ability to express class II antigens on their surface in response to $\gamma$-interferon and tumour necrosis factor making this somewhat unlikely. ${ }^{8}$ Similarly, good clinical results were reported for allogeneic keratinocyte grafts applied to donor sites, where wounds were healed by one week. ${ }^{9-11}$ Several other centres reported apparent take of keratinocyte allografts in burns. In order to determine whether keratinocytes truly survived transplantation, we performed shave excision of a series of tattoos ${ }^{12}$ in patient volunteers. The tattoos were excised to deep dermis or dermis-to-fat junction and then treated with sheets of sex mismatched cultured allogeneic keratinocytes. Biopsy specimens were taken at weekly intervals and examined by in situ hybridisation with a probe to the $\mathrm{Y}$ chromosome (phY2.1). The biopsy specimens showed no evidence of survival of donor keratinocytes, but did show rapid wound healing with recipient cells from the wound edge (appendages had been excised).

Studies of keratinocytes grafted in a transplantation chamber onto nude mice show that deep dermis does not support full epidermal differentiation, ${ }^{13}$ the keratinocytes remaining poorly differentiated and expressing simple epithelial phenotype when close to deep subcutaneous connective tissue. In view of the possibility that the depth of the wound in the tattoo study was influencing the attachment of the allogeneic keratinocytes, so that biological non-attachment rather than immunological rejection was causing the failure of transplantation, the study was repeated in more superficial wounds (routine surgical split thick- 
Table 1 Summary of antibodies used

\begin{tabular}{|c|c|c|}
\hline Antibody & Target antigen & Reference \\
\hline LL017 & Keratin 1 & Leigh et $a l^{16}$ \\
\hline 6B10 & Keratin 4 & van Muijen et al ${ }^{17}$ \\
\hline $\begin{array}{l}\text { LL020 } \\
\text { RCK105 }\end{array}$ & $\begin{array}{l}\text { Keratin } 6 \\
\text { Keratin } 7\end{array}$ & Lane et al ${ }^{18}$ \\
\hline LE41 & $\begin{array}{l}\text { Keratin } 7 \\
\text { Keratin } 8\end{array}$ & $\begin{array}{l}\text { Ramaekers et al } \\
\text { Lane }^{20}\end{array}$ \\
\hline LH2 & Keratin 10 & Leigh et $a l^{16}$ \\
\hline IC7 & Keratin 13 & van Muijen et $a l^{17}$ \\
\hline LL001 & Keratin 14 & Purkis et $a l^{21}$ \\
\hline LH8 & Keratin 14 & Purkis et $a l^{21}$ \\
\hline LL025 & Keratin 16 & Lane et al ${ }^{18}$ \\
\hline & Keratin 17 & Guelstein $e t a l^{2}$ \\
\hline C46 & Keratin $17(+7)$ & Bartek et $a l^{23}$ \\
\hline $\begin{array}{l}\text { LE61 } \\
\text { LP2K }\end{array}$ & $\begin{array}{l}\text { Keratin } 18 \\
\text { Keratin } 19\end{array}$ & $\begin{array}{l}\text { Lane }^{20} \\
\text { Stasiak et al }{ }^{24}\end{array}$ \\
\hline PCO & Collagen IV & Eurodiagnostics, UK \\
\hline $\mathrm{LH} 7 \cdot 2$ & Collagen VII & Leigh et al ${ }^{25}$ \\
\hline HMFG2 & Mucin & $\begin{array}{l}\text { Burchell and Taylor- } \\
\text { Papadimitriou }^{26}\end{array}$ \\
\hline $\operatorname{sm} 3$ & Mucin & $\begin{array}{l}\text { Burchell and Taylor- } \\
\text { Papadimitriou }^{26}\end{array}$ \\
\hline
\end{tabular}

ness skin graft donor sites). All donor sites were healed at seven to 10 days, but there was no evidence of allograft survival. Thus, the depth of the wound was not influential and keratinocyte allografts do not survive transplantation in either superficial or deep surgical wounds.

Although keratinocyte allografts do not survive transplantation, their use has highlighted the fact that autologous and allogeneic keratinocytes can have effects on wound healing apart from take which may be due to synthesis of cytokines ${ }^{14}$ and extracellular matrix proteins. The identification and characterisation of these factors may give rise to recombinant products which can be used in wound healing by incorporation into dressings. Autologous cells, however, are required for graft take.

Keratins are major structural proteins of all epithelial cell types. Their profile appears to be closely related to the differentiated state of a tissue. ${ }^{15}$ The biopsy specimens from the keratinocyte allograft survival studies were used to examine the time course of changes in keratin expression and other markers of differentiation and basement membrane synthesis during wounding.

\section{Methods}

FULL THICKNESS WOUNDS: TATTOO EXCISION

Nineteen patients ( 13 women and six men) requesting removal of decorative tattoos were offered treatment with sheets of cultured allogeneic keratinocytes, and gave their informed consent. The tattoos were excised by serial keratotome excision until all pigment was removed. All wounds removed the deep dermis with hair follicles, and some reached subcutaneous fat. Wounds were treated with sheets of sex mismatched cultured allogeneic keratinocytes and were examined and biopsied weekly until they were healed (three weeks). All biopsy specimens were snap frozen in liquid nitrogen and stored at $-70^{\circ} \mathrm{C}$. Occasional samples were taken following grafting at intervals up to six months.

PARTIAL THICKNESS WOUNDS: DONOR SITES Twenty patients (all women) receiving split thickness skin grafts for chronic leg ulcers were offered keratinocyte allografts to their donor sites as an alternative to paraffin dressing, and gave their informed consent. The wounds were examined and biopsied at seven or 10 days.

\section{CONTROL WOUNDS}

Donor sites for split thickness skin grafts receiving conventional dressings (paraffin gauze) were biopsied at 10 days following grafting. Split thickness skin grafted wounds were also biopsied as controls where possible.

All the wounds were studied by routine immunofluorescence techniques using the monoclonal antibodies listed in table 1, directed against keratin polypeptides, basement membrane proteins, and epithelial mucins.

\section{Results}

The results are summarised in table 2 .

Table 2 Summary of keratin expresion in regenerating wounds

\begin{tabular}{|c|c|c|c|c|c|c|c|}
\hline \multirow[b]{2}{*}{ Keratin } & \multicolumn{3}{|c|}{ Excised tattoo beds (weeks post surgery) } & \multicolumn{2}{|l|}{ Donor sites } & \multicolumn{2}{|l|}{ Split grafts } \\
\hline & One & Two & Three & Seven days & Ten days & Seven days & Six months \\
\hline K1(LL017) & SB & SB & SB & SB & SB & SB & SB \\
\hline $\mathrm{K} 4(6 \mathrm{~B} 10)$ & - & - & - & - & - & - & - \\
\hline K6(LL020) & SB/B & SB & SB & SB & SB & SB & SB \\
\hline K7(RCK105) & - & - & - & - & - & - & - \\
\hline K8(LE41) & - & - & - & - & - & - & - \\
\hline K10(LH2) & SB & SB & SB & SB & SB & SB & SB \\
\hline K13(IC7) & - & - & - & - & - & - & - \\
\hline K14(LLO01) & Pan & Pan & $\mathrm{B}+\mathrm{SB}$ & Pan & Pan & Pan & Pan \\
\hline K14(LH8) & B & B & & B & B & B & B \\
\hline K16(LL025) & SB & SB & SB & SB & SB & SB & SB \\
\hline K17(E3) & SB & SB & SB & SB & SB & & \\
\hline K7/17(C46) & SB & SB & SB & SB & SB & & \\
\hline K18(LE61) & - & - & - & - & - & - & - \\
\hline K19(LP2K) & - & - & - & - & - & - & - \\
\hline Pan-keratin (AE1) & Pan & Pan & SB & Pan & Pan & Pan & Pan \\
\hline Collagen VII(LH7.2) & + & + & + & + & + & & \\
\hline Collagen IV(LH7) & + & + & + & + & + & & \\
\hline Anti-involucrin & EB & SB & SB & + & + & + & + \\
\hline HMFG2 & + & $(+)$ & - & - & - & - & - \\
\hline $\operatorname{sm} 3$ & $(+)$ & - & - & - & - & - & - \\
\hline
\end{tabular}




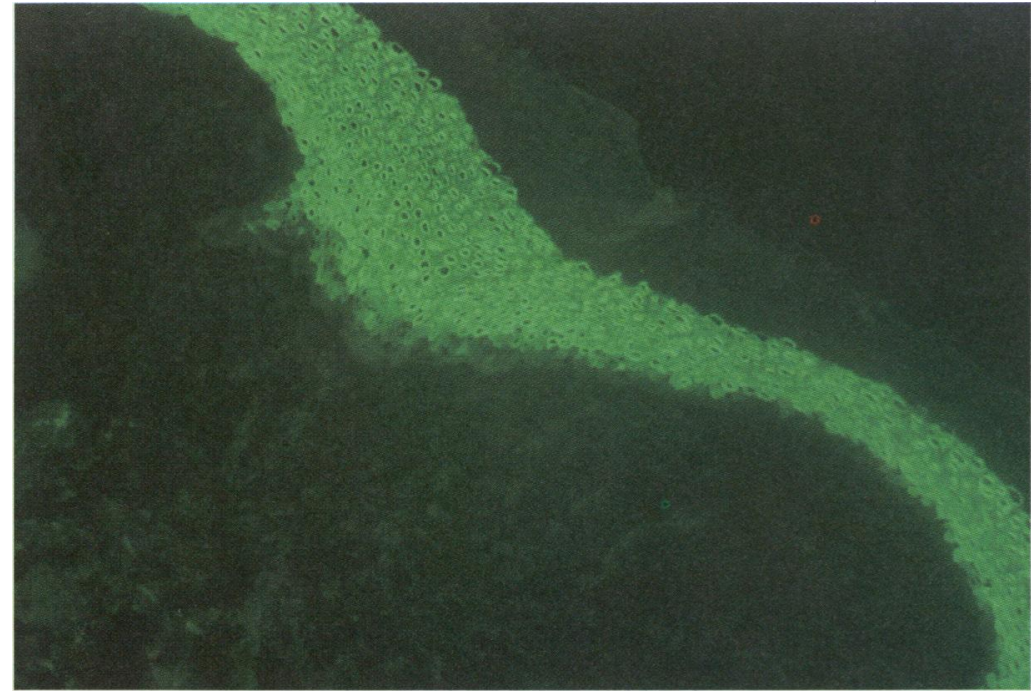

Figure 1 Keratin 1 staining with LL017 two weeks after cultured keratinocyte allografting of an excised tattoo bed.

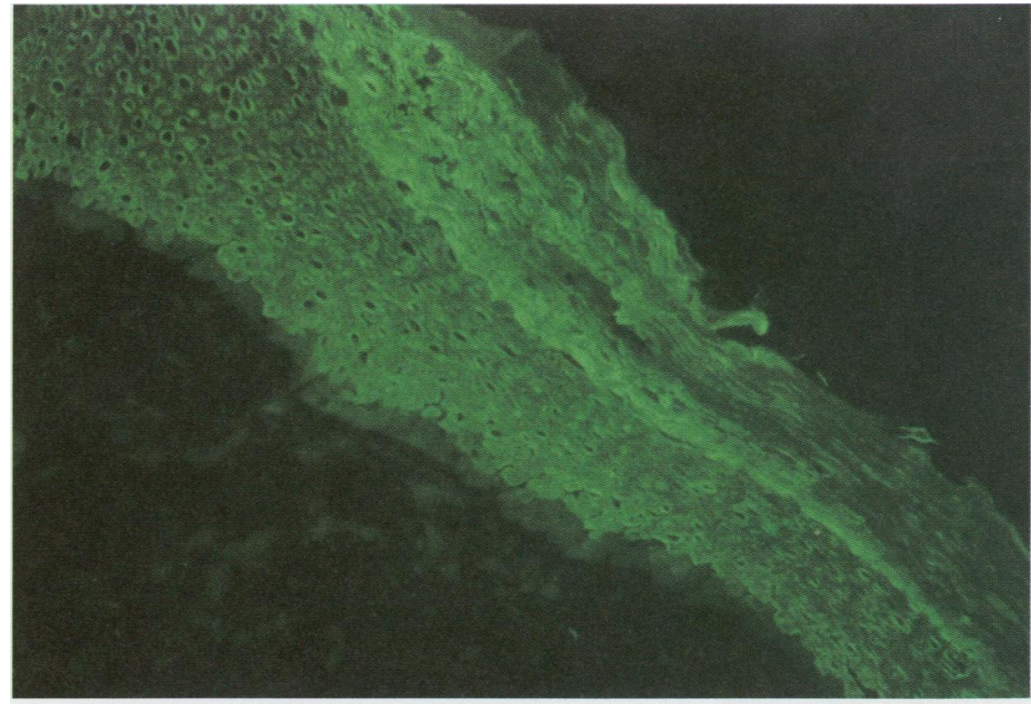

Figure 2 Keratin 10 staining with LH2 two weeks after cultured keratinocyte allografting of an excised tattoo bed.

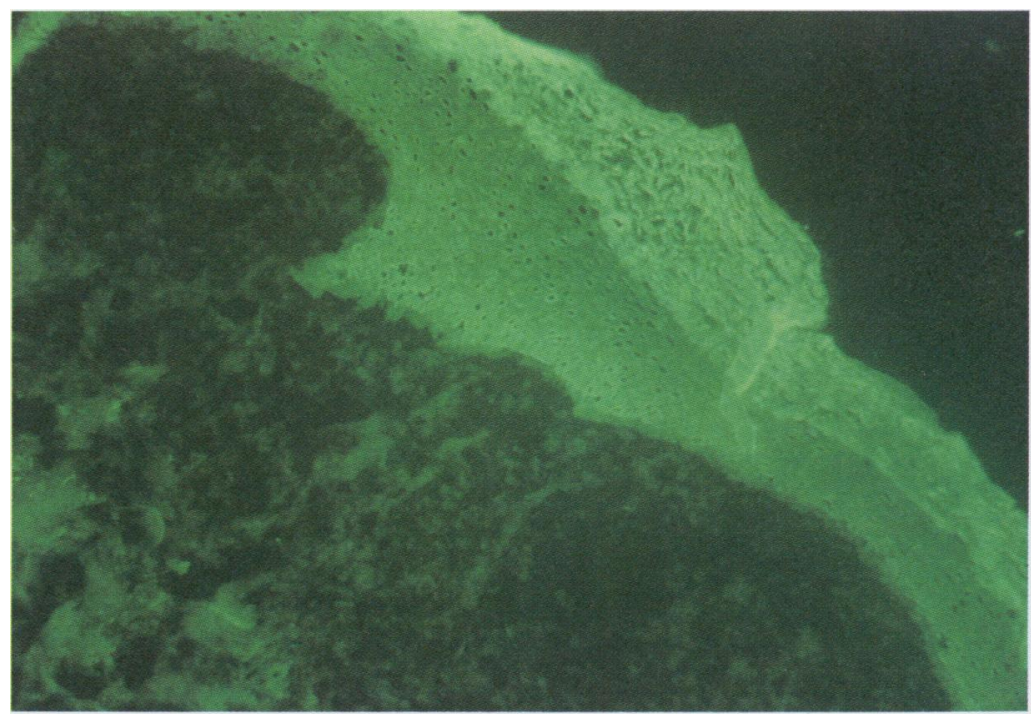

Figure 3 Keratin 6 staining with LLO20 two weeks after cultured keratinocyte allografting of an excised tattoo bed.
WOUND HEALING FOLLOWING KERATINOCYTE ALLOGRAFTING OF EXCISED TATTOO BEDS (FULL THICKNESS) AND DONOR SITES (PARTIAL THICKNESS)

Post-graft biopsy specimens showed a normal appearing epidermis with a flattened dermoepidermal junction. Compact hyperkeratosis and a thickened granular layer, three to four cells deep, was seen. Six months after keratinocyte grafting, the stratum corneum had a normal basket-weave appearance and the granular layer was six cells thick. The epidermis appeared normal and the dermoepidermal junction remained flat with little evidence of rete peg formation. In the donor site wounds the epidermis was better differentiated at one week to 10 days, with cornification and some parakeratosis. The split thickness skin grafts showed a convoluted dermoepidermal junction and an epidermis of essentially normal appearance. An increased dermal mixed cell infiltrate, however, was observed compared with normal skin.

KERATIN EXPRESSION IN FULL THICKNESS AND

PARTIAL THICKNESS WOUNDS

Wherever stratified epidermis was seen, the suprabasal expression of keratins 1 (fig 1) and 10 (fig 2) was found, commencing in the epibasal layer. This occurred at all time points of tattoo and donor site biopsy. The basally restricted epitopes on keratins 5 and 14 were also detected within a single basal cell layer. This was easier to delineate than normal in the absence of rete pegs and dermal papillae. The antibody LL001, showing the full presence of keratin 14 throughout the epidermis, reacted with all epidermal cells in all wounds with no heterogeneity of expression. The reaction was seen throughout the epidermis in first week biopsy specimens of deep wounds, but was lost in the stratum corneum three weeks after tattoo removal.

\section{Hyperproliferation keratins}

Keratins 6 (fig 3) and 16 (fig 4) could be detected suprabasally at all time points after surgery in the tattoos and donor sites. Keratin 6 was also expressed in basal cells. There was no loss of keratin 6/16 expression three weeks after tattoo removal when the epithelium appeared to be normalising morphologically. The few samples from later time points showed that, using the weak monoclonal antibody LMM3, keratin 16 expression was lost at six to eight weeks. Using the strong monospecific antipeptide antibody directed against keratin 16, however, expression of this keratin persisted for longer, although there were insufficient biopsy specimens to determine the exact time of disappearance. In split thickness skin grafts keratin 16 expression was still present six months after surgery. Keratin 17 was coexpressed suprabasally with keratins 6 and 16 . 


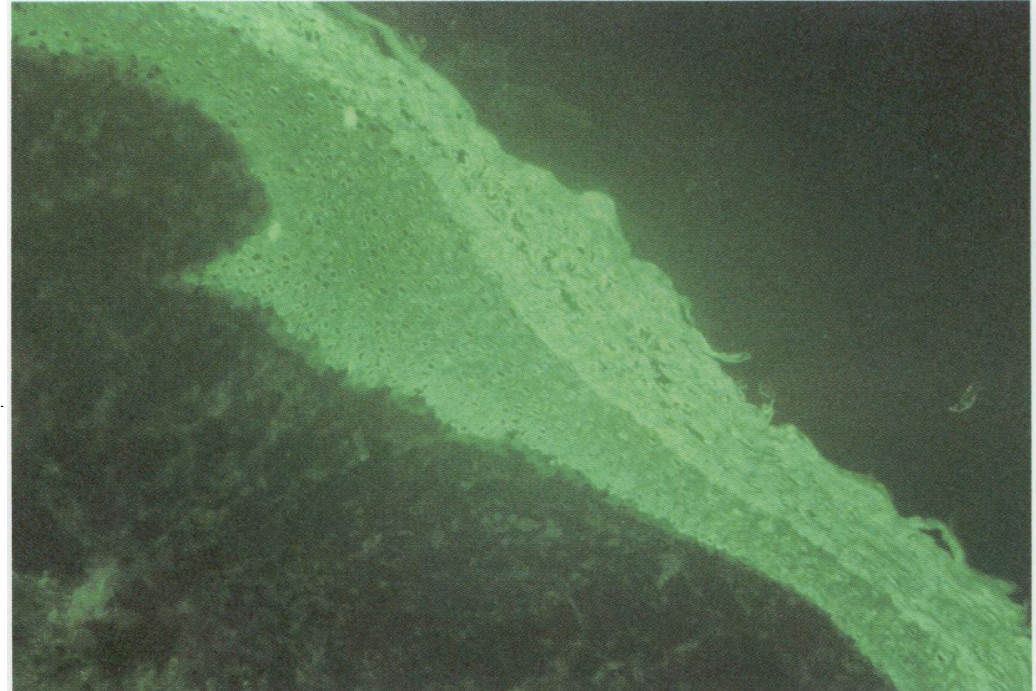

Figure 4 Keratin 16 staining with LL025 two weeks after cultured keratinocyte allografting of an excised tattoo bed.

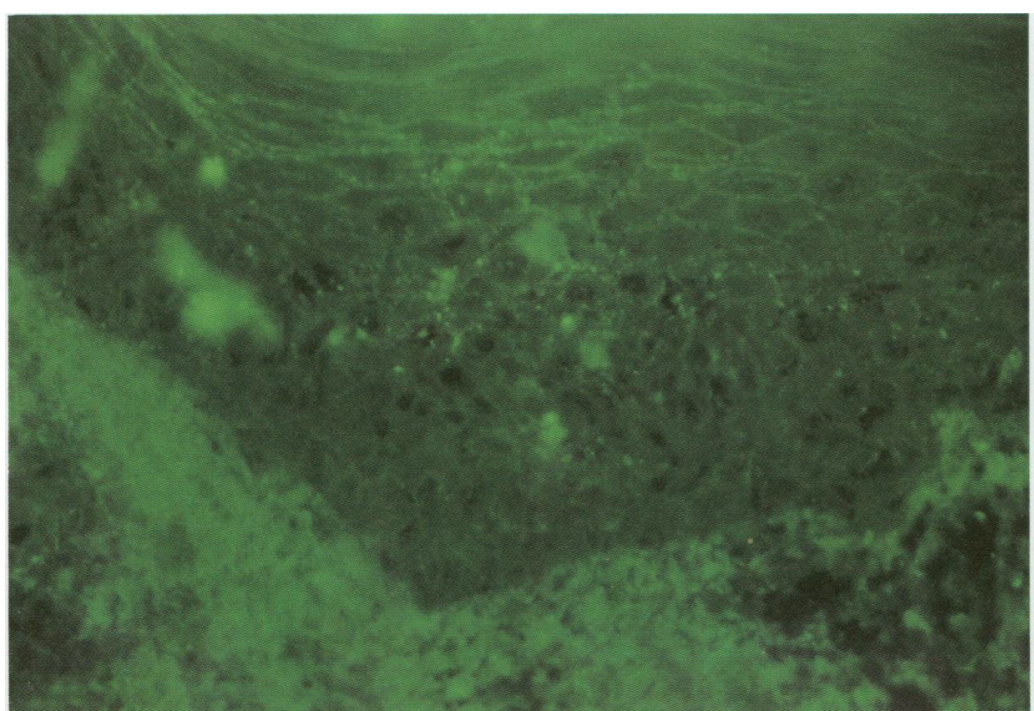

Figure 5 HMFG2 staining one week after cultured keratinocyte allografting of an excised tattoo bed.

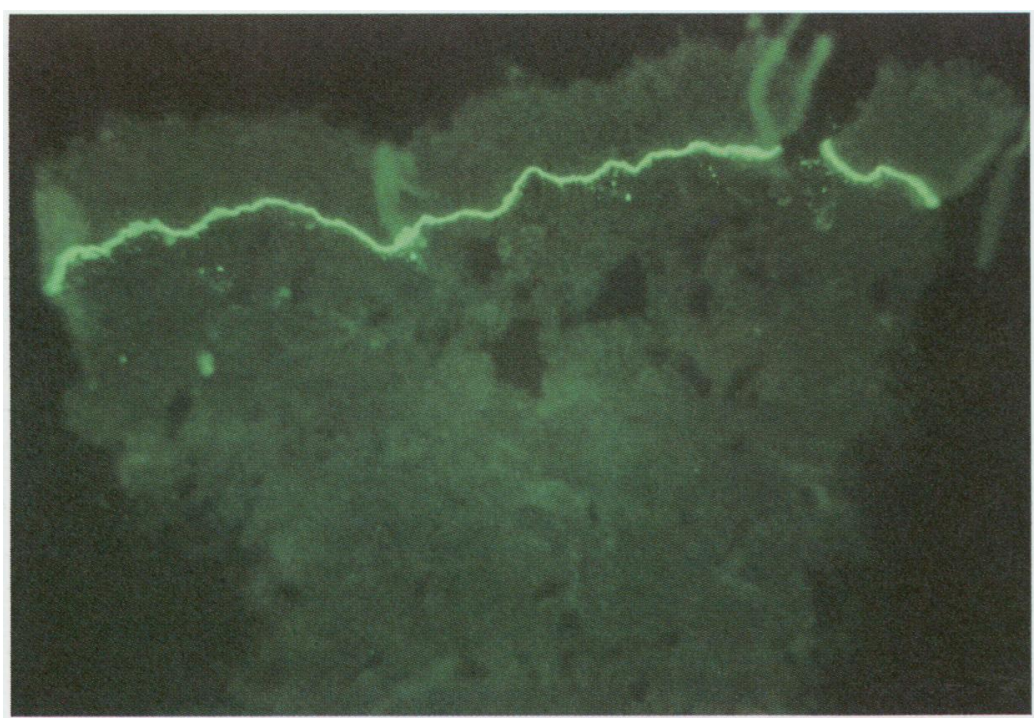

Figure 6 Collagen VII staining with LH $7 \cdot 2$ two weeks after cultured keratinocyte allografting of an excised tattoo bed.
Mucosal keratins and simple epithelial keratins

There was no evidence of the simple epithelial keratins $7,8,18,19$, or mucosal keratins 4 / 13 in any interfollicular site at any time after wounding. The donor site specimens retaining appendages acted as internal controls for the simple epithelial keratins, as their luminal sweat gland cells stained positively. Mucosal samples from gingiva acted as positive controls for keratin 4/13 staining.

\section{INVOLUCRIN EXPRESSION}

In the tattoo wounds at one week involucrin staining was present in epibasal cells at the cell periphery, but at two weeks it was reverting to its normal position at the periphery of cells in the upper stratum spinosum. At three weeks the position and staining were comparable with normal skin.

\section{MUCINS}

Epithelial mucins could be detected mainly at one week after tattoo excision. The staining was focally suprabasal and was polarised within the cell to the upper border. Antibody HMFG2 stained suprabasal tattoo biopsy specimens two to three cell layers above the basal cell compartment, but not into the stratum corneum, with small amounts of suprabasal staining at two weeks and none at three weeks (fig 5). No staining was seen in the donor site biopsy specimens. The antibody $\mathrm{sm} 3$ reacts with the core protein of the HMFG2 antigen and is usually only exposed during altered glycosylation such as during tumorigenesis. This antigen could be detected in a limited number of suprabasal keratinocytes in the tattoo biopsy wounds at one week only, and within the population of $\mathrm{HMFG} 2$ positive cells.

\section{BASEMENT MEMBRANE STRUCTURE}

Wherever the wounds were epithelialised, all basement membrane proteins could be detected immunohistochemically at the dermoepidermal junction. Type IV collagen was present in vascular and epidermal basement membranes in the tattoo biopsy specimens taken at one week, but the staining was ragged and more diffuse than normal skin. There was also a high level of dermal staining distinct from the basement membrane zone, but spread diffusely throughout the connective tissue, which was reproducible and clearly not artefactual. This was thought to be associated with rapid tissue remodelling. Type VII collagen reaction was limited to epidermal basement membranes and was seen at all epithelial sites (fig 6). Unfortunately, no wound edges could be seen as the biopsied areas were uniformly epithelialised, so the relation of basement membrane zone synthesis to wound edge could not be determined. Some diffuse staining of connective tissue was seen in the tattoo biopsy specimens taken at one week, but this had disappeared by two weeks. 


\section{Discussion}

In the deep wounds the appendages were removed as was most of the dermis. The contour and general morphology were strikingly flattened and the epidermal healing must have come from the cut edge of the wound. However, the changes in keratin expression were identical with changes found in interfollicular epidermis in more superficial wounds. Because of the form of treatment, biopsy specimens only showed epidermis with an intact basement membrane and changes in the advancing tongue against mesenchyme were not seen.

This study confirms that keratin 16 , as detected by monoclonal antibodies, is normally expressed in wounds with keratin 6: the hyperproliferative keratin pair, ${ }^{27}$ although keratin 6 expression precedes that of keratin 16. These keratins are constitutively expressed in certain stratified squamous mucosal epithelia ${ }^{28}$ and the skin of palm and sole (areas subjected to repeated minor trauma), but have not been found biochemically in normal epidermis of other sites external to the outer hair root sheath and junctional region. ${ }^{29}$ They have been demonstrated suprabasally in the epidermal hyperproliferation seen in psoriasis and other epidermal pathology including benign tumours, such as keratoacantomas and warts. ${ }^{27}$ Our study has shown that keratin 16 persists in keratinocyte grafted deep wounds for up to six weeks, and up to six months in split thickness skin grafted wounds. Although keratins 6 and 16 have not been detected in normal skin, Stoler $e t a l^{30}$ have found the relevant mRNAs present in normal skin. This raises the possibility that regulation is occurring at a posttranscriptional level, allowing a rapid response to injury with changes in the keratinocyte cytoskeleton that may aid cell migration. In this sense the keratin $6 / 16$ pair might be considered mucoregenerative rather than hyperproliferative. The fact that this expression persists for weeks to months suggests a continuing process of migration, or an additional, more prolonged and undetermined advantage resulting from that expression.

The normal suprabasal keratins in skin (1/ 10) were also found in wound cells. There was therefore clear evidence of suprabasal coexpression of the differentiation keratins 1 and 10 and the hyperproliferative keratins 6 and 16 in the wound healing epidermis in the same cells. This does not, however, exclude a quantitative reduction in expression of keratins $1 / 10$ as seen on gels in epidermal hyperproliferation in psoriasis. ${ }^{31}$

Glycosylation of membrane glycoproteins is associated with epidermal differentiation, and this process is altered in wound healing and hyperproliferation such as psoriasis. The expression of human milk fat globule mucins in skin has not been reported except in retinoid treated skin, but presumably reflects this known altered termination of glycosylation.

Studies of the regenerating basement membrane zone in wounds both in animal models such as the primate and rodent, and in the few human studies performed, have shown that the components are not synthesised synchronously.
The emergence of laminin, fibronectin and collagen VII lags behind the re-epithelialisation which is associated with the presence of bullous pemphigoid antigen (BPA) and collagen IV. This may reflect the likelihood that BPA and collagen IV provide a framework onto which other basement membrane zone components attach. Type VII collagen probably requires formation of a neodermis rather than granulation tissue to provide an attachment (or anchoring) plaque. Anchoring fibrils were found to be slow in appearance and maturation in previous studies of keratinocyte grafted wounds. $^{32}$

Following keratinocyte grafting the healing skin expresses the hyperproliferative phenotype throughout the first three weeks after grafting, despite epithelialisation having occurred. Thus, these markers are the most sensitive for altered epidermis following wounding. This has some significance to both the production of composite skin grafts in the laboratory, and to the clinical grafting of partial thickness defects. In the former case, although cultured keratinocyte sheets express the keratin 6/16 pair, the expression appears subjectively decreased to varying degrees in composite grafts, in a reciprocal fashion to the differentiation keratin 1/10 pair. Quantification of keratin 6/16 expression may, therefore, become a measure of the quality of such composites. One might envisage a degree of expression which represents a compromise between the differentiation required for graft stability on the one hand, and the regenerative capacity capable of providing the necessary signals (for example, cytokines) for graft vascularisation and complete healing without scars on the other. In the latter case quantification of the keratin 6/16 pair in partial thickness wounds by punch biopsy might offer some more objective assessment of the need for split thickness skin grafting.

In cultured keratinocyte grafted wounds the dermoepidermal junction remains flat and, although a basement membrane is laid down helping to anchor keratinocytes, they are still likely to be vulnerable to shearing forces. Clearly, split thickness skin grafted wounds have an advantage as they maintain the convolution of the dermoepidermal junction, even though hyperproliferative keratins appear to persist longer than keratinocyte grafted wounds. The time course of expression of regulatory cytokines will be of considerable interest.

Mr S R Myers is generously sponsored by the Restoration of Appearance and Function Trust (RAFT) at Mount Vernon Hospital, Northwood, Middlesex.

1 Green H, Kehinde O, Thomas J. Growth of cultured human epidermal cells into multiple epithelia suitable for grafting. Proc Natl Acad Sci USA 1979;76:5665-8.

2 Phillips TJ, Kehinde O, Green H, Gilchrest BA. Treatmen of skin ulcers with cultured epidermal allografts. $\mathcal{F ~} \mathrm{Am}$ Acad Dermatol 1989;21:191-9.

3 Hancock KA, Leigh IM. Cultured keratinocytes and keratinocyte grafts. Skin grafts from the laboratory can supplement autografts. BMF 1989;299:1179-80

4 O'Connor NE, Mulliken JB, Banks-Schlegel S, Kehinde O, Green $H$. Grafting of burns with cultured epithelium prepared from autologous epidermal cells Lancet $1981 ; \mathbf{i}$ : 75-8.

5 Hefton JM, Madden MR, Finkelstein JL, Shires GT. Grafting of burn patients with allografts of cultured epidermal ing of burn patients with allo
cells. Lancet $1983 ;$ ii: $428-30$. 
6 Madden MR, Finkelstein JL, Staiano-Coico L, Goodwin $\mathrm{CW}$, Shires GT, Nolan EE, et al. Grafting of cultured CW, Shires GT, Nolan EE, et al. Grafting of cultured allogeneic epidermis on second and third degree
wounds on 26 patients. $f$ Trauma $1986 ; 26: 955-60$.

7 Hefton JM, Amberson JB, Biozes DG, Weksler ME. Loss of HLA-DR expression by human epidermal cells after growth in culture. $F$ Invest Dermatol 1984;83:48-50.

8 Morhenn VB, Benike CJ, Cox AJ, Charron DJ, Engleman EG. Cultured human epidermal cells do not synthesize HLA-DR. F Invest Dermatol 1982;78:32-7.

9 Thiovolet J, Faure M, Demidem A, Mauduit G. Long term survival and immunological tolerance of human epidermal allografts produced in culture. Transplantation 1986;42: 274-80.

10 Thiovolet J, Faure M, Demidem A. Cultured human epidermal allografts are not rejected for a long period. Arch Dermatol Res 1986;278:252-4.

11 Faure M, Mauduit G, Schmitt D, Kanitakis J, Demidem A, Thiovolet J. Growth and differentiation of human epidermal cultures used as auto and allografts in humans. Br $\mathcal{F}$ Dermatol 1987;116:161-70.

12 Brain A, Purkis P, Coates P, Hackett M, Navsaria H, Leigh I. Survival of cultured allogeneic keratinocytes transplanted to deep dermal bed assessed with probe specific for Y chromosome. BMF 1989;298:917-19.

13 Schweizer J, Winter H, Hill MW, Mackenzie IC. The keratin polypeptide patterns in heterotypically recombined epithelia of skin and mucosa of adult mouse. Differentiation 1984;26:144-53.

14 McKay IA, Leigh IM. Epidermal cytokines and their roles in cutaneous wound healing. Br 7 Dermatol 1991;124: 513-18.

15 Lane EB, Bartek J, Purkis PE, Leigh IM. Keratin antigens in differentiating skin. Ann NYAcad Sci 1985;455:241-58.

16 Leigh IM, Purkis PE, Whitehead P, Lane EB. Monospecific antibodies to keratin 1 carboxy terminal (synthetic peptide) and to keratin 10 as markers of epidermal differentiation. Br 7 Dermatol 1993;129:110-19.

17 van Muijen GNP, Ruiter DJ, Franke WW, Achtstatter T, Haasnoot WH, Ponec $M$. Cell type heterogeneity of cytokeratin expression in complex epithelia and carcinomas as demonstrated by monoclonal antibodies specific for as demonstrated by monoclonal antibodies specific for

18 Lane EB, Wilson CA, Hughes BR, Leigh IM. Stem cells in hair follicles. Ann N Y Acad Sci 1991;461:197-213.

19 Ramaekers FCS, Huysmans A, Schaart G, Moesker O, Vooijs $P$. Tissue distribution of keratin 7 as monitored by a monoclonal antibody. Exp Cell Res 1987;170:235-49.
20 Lane EB. Monoclonal antibodies provide specific intramolecular markers for the study of epithelial tonotramolecular markers for the study of epithelial

21 Purkis PE, Steel JB, Mackenzie IC, Nathrath WR, Leigh IM, Lane EB. Antibody markers of basal cells in complex epithelia. F Cell Sci 1990;97:39-50.

22 Guelstein VI, Tchypysheva TA, Ermilova VD, Litvinova LV, Troyanovsky SM, Bannikov GA. Monoclonal antibody mapping of keratins 8 and 17 and of vimentin in normal human mammary gland, benign tumors, dysplasias and breast cancer. Int 7 Cancer 1988;42:147-53.

23 Bartek J, Vojtesek B, Staskova Z, Bartkova J, Kerekes Z, Rejthar A, et al. Series of 14 new monoclonal antibodies to keratins: characterization and value in diagnostic histopathology. F Pathol 1991;164:215-24.

24 Stasiak PC, Purkis PE, Leigh IM, Lane EB. Keratin 19: Predicted amino acid sequence and broad tissue distribution suggest it evolved from keratinocyte keratins. $\mathcal{f}$ tribution suggest it evolved from

25 Leigh IM, Purkis PE, Bruckner-Tuderman. LH 7.2 monoclonal antibody detects type VII collagen in the sublamina densa zone of ectodermally-derived epithelia including skin. Epithelia 1987;1:17-19.

26 Burchell J, Taylor-Papadimitriou J. Antibodies to human milk fat globule molecules. Cancer 1989;7:53-61.

27 Weiss RA, Eichner R, Sun T-T. Monoclonal antibody analysis of keratin expression in epidermal diseases: a 48- and 56-kdalton keratin as molecular markers for hyperproliferative keratinocytes. I Cell Biol 1984;98:1397-406.

28 proliferative keratinocytes. Fell Biol 1984,98.139 Muijen GNP, Lane EB. Site variation in keratin expression in human oral epithelia - an immunocytochemical study of human oral epithelia-an immunocytochem

29 Wilson CL, Dean D, Lane EB, Dawber PP, Leigh IM. Keratinocyte differentiation in psoriatic scalp: morphology and expression of epithelial keratins. Br f Dermatol 1994; 131:191-200.

30 Stoler A, Kopan R, Duvic M, Fuchs E. Use of monospecific antisera and CRNA probes to localize the major changes in keratin expression during normal and abnormal epidermal differentiation. $f$ Cell Biol 1988;107:427-46.

31 Bowden PE, Wood EJ, Cunliffe WJ. Comparison of prekeratin and keratin polypeptides in normal and psoriatic keratin and keratin polypeptides in normal and psoriatic

32 Woodley DT, Peterson HD, Herzog SR, Stricklin GP, Burgeson RE, Briggaman RA. Burn wounds resurfaced by cultured epidermal autografts show abnormal reconstitution of anchoring fibrils. $\mathscr{f} A M A 1988 ; 259: 2566-71$. 